\title{
Escuelas y barrios cercados: entre la contención social y la contención educativa
}

\author{
Renata Giovine*
}

Resumen: La hipótesis planteada es que el giro discursivo que se produce a comienzos del siglo XXI ante el ocaso de la reforma educativa de los ' 90 en Argentina, si bien responderá inicialmente a una urgencia, irá conformando una trama de sentido heterogénea con una visión estratégica dominante. Esta trama se reconstruye del análisis principalmente de legislación derivada del ámbito bonaerense que formaliza la constitución de redes entre organismos gubernamentales de educación, minoridad y familia, individuos y organizaciones de la sociedad civil para el gobierno de la pobreza. Se estructura así un discurso que oscila entre la estigmatización y la reparación de derechos, poniéndose en evidencia cómo las escuelas por sí solas no bastan y emergen otras estrategias que las cercan en un espacio territorial separado del resto de la comunidad. Micro-comunidades en las que habitan aquellos que luchan por constituirse en beneficiarios y/o dadores de planes y programas, cuyo objetivo estratégico será la contención social y educativa.

Palabras clave: políticas educativas y sociales; redes; contención; micro-comunidades; gobierno de la pobreza.

\section{Schools and fenced slums: between social welfare and educational}

Abstract: Whe start with a hypothesis: the discursive shift that occurs in the early twentyfirst century with the decline of Argentinian's 90's educational reform, although initially responding to an emergency, will build an heterogeneous plot of sense with a dominant strategic vision. This plot is reconstructed by analyzing mainly Buenos Aires's secondary legislation which formalizes networking among government agencies of education, minorities and family, individuals and civil society organizations for the management of poverty. The resulting discourse moves between the stigma and repair of rights, putting in evidence how schools alone are not sufficient, and how other emerging strategies hedge schools in a territorial space separated from the rest of the community. Micro-communities that have those struggling to become beneficiaries and/or participants of plans and programs, whose strategic objective is the social and educational containment.

Key words: educational and social policies; networks; containment; micro-communities; government of poverty.

Núcleo de Estudios Educativos y Sociales - Facultad de Ciencias Humanas - Universidad Nacional del Centro de la Provincia de Buenos Aires (NEES-FCH-UNCPBA), Argentina. renatagiovine@ gmail.com

Pro-Posições, Campinas, v. 23, n. 1 (67), p. 27-42, jan./abr. 2012 


\section{Introducción}

Diciembre de 2001 representó para la Argentina algo más que una profunda crisis político-institucional, también significó el ocaso de las llamadas reformas educativas de los '90, portadoras de un discurso redentor basado en ese relato de la posibilidad de un desarrollo cultural a escala mundial, la creencia en la educación como un universal evolutivo - para utilizar la terminología parsoniana- y "palanca" para la re-modernización y el reordenamiento moral de los individuos, las instituciones y los países.

El reclamo que invadió las calles sintetizado en la expresión "Que se vayan todos" refuerza la idea tocquevilleana basada en "la pureza y la bondad de la sociedad civil frente a la suciedad y la maldad de la política y el estado" (Garretón, 2002). Este nuevo "colapso" en la democracia argentina -débil e incompleta (Garretón, 2000; Lanzaro, 2001)- habilita un giro discursivo en las políticas educativas y sociales que, si bien inicialmente responderá a una urgencia, irá conformando una trama de sentidos heterogénea con una visión estratégica dominante (Foucault, 1983). Un entramado en el que se observan vocabularios, principios, decisiones, leyes y formulaciones científicas que remite a lógicas contradictorias y superpuestas, en las que se amalgaman las pretensiones neoliberales de constituir un "gobierno propiedad de la comunidad" como herramienta eficaz para combatir el clientelismo enquistado en las burocracias estatales y los "profesionales de los servicios" (Osborne y Gaebler, 1994: 912); el reconocimiento de los derechos de grupo vinculados al respeto a la diversidad cultural que apunte hacia una ciudadanía más compleja y más inclusiva; la implementación de políticas redistribucionistas para los sectores que más dramáticamente sintieron el peso del proyecto de modernización excluyente de los ' 90 , en las que - pese a la proclama de la primera-se entremezclan el derecho y la prebenda; y por último, la reactualización de discursos de la inseguridad asociados al "retorno de las clases peligrosas" (Castel, 2004) que modifican el sentido de las políticas sociales y su corrimiento hacia la "prevención social de la criminalidad" (Baratta, 1997).

I. La manifestación popular produjo la caída del gobierno de la Alianza -coalición política que logró derrotar al menemismo luego de diez años de gobierno-. La Alianza estaba integrada por la Unión Cívica Radical y un Frente (FREPASO) constituido por el Frente Grande, el PAIS (ambos disidentes del peronismo y de izquierda) y el socialismo. Como afirma Novaro (200 I), como coalición legislativa opositora logrará desde su conformación poner límites al gobierno de Carlos Menen, generando un mayor espacio para el debate y el control de gestión, como así también ampliando la competencia y colaboración entre partidos. Sin embargo, una vez en el gobierno en 2000 -y a pesar de haber logrado mayoría en la Cámara de Diputados- no podrá resolver los problemas del nuevo escenario político, algunos heredados y otros inherentes a la composición de su propia fuerza política, al perfil indefinido y de bajo tinte carismático de quien asume la presidencia, Fernando De la Rúa.

2. Libro considerado paradigmático de la reforma educativa del denominado programa de gobierno estadounidense América 2000. 
El principal interrogante que guía el análisis de este artículo es cómo se re-estructura un discurso de orden para el gobierno de la pobreza en el que perviven y se superponen estas lógicas, a la vez de responder a los requerimientos de inclusión en un contexto fuertemente desigual. Una desigualdad más compleja ya no sólo anclada en la clase social, sino diversificada en una variedad de aspectos: geográficos, ecológicos, generacionales, de género, salariales, informáticos, laborales, educativos, entre otros. Pero con un núcleo invariante: la participación -o no- en el mercado, en un momento como el actual en el que el consumo se convierte en una nueva fuente productora de sentido, en uno de los principales referentes identitarios de la niñez y la juventud. Una desigualdad más compleja que adquiere un carácter flexible y dinámico involucrando, como afirman Fitoussi y Rosanvallon (1997), a toda la sociedad y no solamente a esa tradicional frontera que delimitaba los excluidos de los incluidos. En la primacía de una matriz mercado-céntrica, la exclusión se vive más bien en términos de expulsión de aquellos individuos que quedan fuera de la red de consumo y de la garantía jurídica de sus derechos sociales en un estado que se descentra, una sociedad que cada vez más se judicializa ${ }^{3}$ y escuelas públicas que pierden gran parte de su capacidad de socializar en un espacio común a la mayoría de los argentinos. Al quedar sometidos a la voluntad y fluctuaciones de las reglas del mercado que se rigen por la competencia -y no por la solidaridad-, por la seguridad jurídica $-\mathrm{y}$ no política-y la responsabilidad individual $-\mathrm{y}$ no social-; la expulsión se vive como constante amenaza, como horizonte de posibilidad también para los incluidos ${ }^{4}$.

Para intentar responder al interrogante anteriormente planteado, a continuación se presentarán algunos resultados de una indagación sobre las políticas educativas y sociales en el estado de la Provincia de Buenos Aires entre 1999 y $2006^{5}$ para incluir, retener y contener social y escolarmente a los niños, adolescentes y jóvenes en situación de viejas y nuevas pobrezas. Ese segmento de la población pasa de ser estadísticamente pobre a ser socialmente visto y tratado como pobre, con la consecuente institucionalización y legalización de las desigualdades (Tenti en Dallorso, 2008: 24). Y se constituye en objeto de intervención de una multiplicidad de polí-

3. El fenómeno de judicialización tiene lugar cuando ante la conflictividad creciente se observa un corrimiento de las decisiones políticas hacia las judiciales, combinándose principios de culpabilización y prevención.

4. La solidaridad, seguridad y responsabilidad social eran los componentes básicos de esa tríada en la que se edificó el welfare state principalmente en Europa, cuya versión latinoamericana fue la matriz estado-céntrica.

5. Se parte de 1999, ya que es el año en el que se detectó, a partir de un rastreo exploratorio amplio de la legislación educativa básica y derivada de las décadas de los ' 90 y 2000, cómo empiezan a proliferar leyes, documentos, programas y proyectos oficiales, cuyos objetivos principales serán la seguridad (Ley no 12299/99: Programa Provincial de Prevención de la Violencia Escolar) y la inclusión escolar de niños, adolescentes y jóvenes en situación de pobreza.

Pro-Posições, Campinas, v. 23, n. 1 (67), p. 27-42, jan./abr. 2012 
ticas locales estatales y no estatales, clasificándoselos -junto a las escuelas a las que asisten o debieran asistir-como "marginados/les", "de alto/en riego", "vulnerables". A la vez se los fija a un espacio territorial con pretensiones de autorregulación y con el riesgo que ello supone para la construcción del lazo social.

\section{Los límites de las escuelas en el gobierno de la pobreza}

La complejidad de la realidad política y económica argentina en un momento de una nueva crisis político-institucional y económica -Diciembre de 2001- echa por tierra las promesas del discurso del gran concierto de naciones, de esa dimensión planetaria -global- reforzadora del mito de la "gran familia de los hombres" (Barthes), en tanto destino inexorable al que se iba a embarcar la Argentina de los '90. También echa por tierra ese otro mito integrador de la sociedad argentina fuertemente asociado a la idea de una clase media fuerte y culturalmente homogénea formada en la escuela pública en tanto espacio de "educación común". Por el contrario, las investigaciones mostrarán los ganadores y perdedores del proyecto modernizador (Svampa, 2000; 2002), abriendo a una heterogeneidad de experiencias que redefine las vinculaciones del individuo con las instituciones, el estado y una sociedad que se fragmenta en micro-comunidades habilitando un conglomerado de multi-regulaciones.

Del análisis del cuerpo documental trabajado se observa cómo las escuelas públicas transmutan en escuelas para pobres y empobrecidos, siendo requeridas como espacios de "contención social y afectiva” (Director General de Cultura y Educación José O. Bordón en Honorable Legislatura de la Provincia de Buenos Aires, 2001), como ese "pedazo de estado que queda en los barrios" (Director General Mario Oporto en Honorable Legislatura de la Provincia de Buenos Aires, 2002: 8), encontrándose atrapadas en las miserias de un estado que apenas podrá suministrar algunos de los servicios básicos ${ }^{6}$, en tanto otros volverán a ser considerados "medidas de adaptación a la crisis presupuestaria” 7 . Por un lado se evidencia una inflación de asistencialismo escolar, por otro cómo las escuelas por sí solas no bastan y cómo se va demandando y reconociendo la intervención de otras áreas gubernamentales,

6. "En estos días muchos Consejos Escolares no tienen luz, porque se les ha cortado el suministro... Como medida, las empresas, para no castigar tanto a las escuelas, han atacado fundamentalmente un lugar como el Consejo Escolar, donde no se dictan clases" (senador Irigoin en Honorable Legislatura de la Provincia de Buenos Aires, 2002: 9)

7. Algunas de las medidas que se tomaron en el área educativa como parte de la emergencia económica (Ley 12.727/0 I) son: eliminación de horas cátedras como "modalidad retributiva por la prestación de servicios que no tenga estricta naturaleza docente frente a alumnos" (artículo $2^{\circ}$ de la Ley $n^{\circ}$ 12.867/02) y de reparticiones en el organismo central de la Dirección General, nuevo régimen de licencias y jubilaciones, reclasificación de las escuelas y fusión de cursos, nuevos métodos de "focalización de Becas", creación de un Fondo de Descentralización de la Gestión Administrativa y "potenciar recursos locales". 
principalmente aquellas vinculadas a las políticas sociales y de otros sectores comunitarios. Es decir, comenzará un proceso de formalización y organización a nivel central (nacional y provincial) de nuevas cristalizaciones burocráticas de "gestión integral' tanto al interior como al exterior del sistema educativo.

Estas nuevas demandas se evidencian en un nivel normativo que en las ciencias jurídicas se denomina legislación derivada: resoluciones, planes, programas, proyectos, informes de gestión y otros documentos oficiales que se elaboran en un nivel inferior de la pirámide jurídica. Aquella que se produce en el propio aparato burocrático del sistema educativo bonaerense, respondiendo a necesidades de regulación y control más inmediatas de la vida cotidiana de las instituciones escolares. Esa franja de normativización y normalización -muchas veces superpuesta y contradictoria de diferentes temporalidades y lógicas- en la cual algunas de las tensiones y propuestas que no llegan a plasmarse en constituciones ni en leyes ${ }^{8}$, encontrarán intersticios para concretarse en ese espacio "interno" de lo escolarizado. Una legislación muy prolífera, de difícil recopilación, pero cuya significatividad radica en que, además de reglamentar las leyes, en muchas ocasiones avanza sobre ellas, llena algunos espacios vacíos característicos de la incompletud del Derecho o anticipa modificaciones que luego se plasmarán en las reformas legislativas posteriores ${ }^{9}$.

Estas prescripciones se han sistematizado en tres grandes tipos. En primer lugar, aquellas tradicionales que -mayoritariamente en forma de resolucionescontinúan legislando para un conjunto o colectivo (el sistema, el nivel educativo primario o medio, por ejemplo). Junto a esta modalidad normativa, surgen esas otras figuras jurídicas denominadas programas y proyectos especiales, a los cuales se ligan financiamientos específicos, provisión de equipamiento o mejoras edilicias, pedagógicas o institucionales. Este tipo de normas va instituyendo una trama regulatoria que envuelve a las escuelas y las compele a múltiples requerimientos por parte de los niveles nacional y provincial del estado con objetivos diferentes, como así también de otras organizaciones gubernamentales y no gubernamentales que intervienen en la definición de objetivos y contenidos educativos.

Así se introducen desde el propio estado una serie de filtros adicionales al interior del sistema educativo, a través de normativas que ya no legislan para el conjunto,

8. Las normas educativas generales -llamadas legislación básica- en el período analizado continúan siendo las sancionadas entre 1991 y 1995, las cuales reafirman el dominio estatal en el gobierno del sistema educativo. Un dominio que en Argentina se basa en una disputa entre el nivel nacional y provincial, que en el caso de la Provincia de Buenos Aires es una cuestión constitutiva en la lucha por la hegemonía de uno sobre otro nivel estatal. Véase por ejemplo Halperín Donghi ( 1980) para la historia de la formación del estado nacional; como Pineau (I 997) y Giovine (2008) para la constitución del sistema educativo bonaerense.

9. Tales como las leyes educativas actualmente vigentes: Ley Nacional de Educación n 26206/06 y Ley Provincial de Educación n 13.688/07. 
sino que individualizan y responsabilizan a determinadas escuelas, docentes y alumnos de ser beneficiarios o no de los bienes - materiales y simbólicos-que reparte. Una figura jurídica que produce otros efectos de poder que se distancian de la lógica del universalismo legal característico del estado de derecho, materializado a través de normas impersonales de validez general. Los proyectos especiales se acercan más a una intervención puntual y focalizada que potencialmente gana en equidad, a la vez que se basan no tanto en la prevención, sino en la carencia o déficit que poseen las instituciones e individuos, muchos de los cuales deberán competir entre sí para ser merecedores de los beneficios que traen aparejado.

Así se particularizan los objetos de intervención y las tareas de inspección y evaluación; las cuales ya no sólo se centran en la normalización del trabajo de docentes y alumnos, a través de las ciencias de la administración que suponían la burocratización de las actividades educativas en base a regulaciones que posibilitaban una intervención general, prescriptas en las facultades otorgadas a las diferentes instancias de gobierno del sistema educativo (Giovine, 2008). Más bien se acrecientan los requerimientos a las escuelas por parte de diversos centros de regulación, siendo compelidas a adquirir nuevas visibilidades y publicidades tanto al interior del sistema educativo, como para un afuera al que se lo habilita -de diferentes formas- a intervenir. Tareas de asignación y control que hacen hincapié en las "debilidades detectadas" en vez de en "las necesidades posibles de ser asistidas" (Ball, 2001) ${ }^{10}$; pasándose así de un proceso positivo de adjudicación, inspección y evaluación a otro negativo basado en la carencia y el riesgo.

Durante 1999-2006 se observa cómo aumentan en este tipo de normativas especiales aquellas que tienen como objetivo incluir, retener y contener para aliviar una pobreza que, como se ha mencionado anteriormente, se diversifica y a la cual se aboca el sistema de escolarización estatal. Puede citarse a modo de ejemplo al Programa de Centros de Actividades Juveniles del ministerio nacional (2001), al que la Provincia suscribe en 2004; el convenio de Seguridad Externa de los establecimientos educativos (2000) entre la Dirección General de Cultura y Educación y la Secretaria Provincial de Seguridad; el Servicio Alimentario Escolar dependiente del Ministerio de Desarrollo Humano de la Provincia; y los planes educativos y sociales que se reformulan en el comienzo del siglo XXI que habían surgido bajo el amparo económico del Fondo de Reparación Histórica del Conurbano (1990-2001) que, si bien su vigencia es anterior al período analizado aquí, es significativo para los fines de este trabajo (al cual se hará referencia en el próximo apartado).

La creación de las Unidades Educativas de Gestión Distrital en 2003 es un indicio de cómo se introducen otros dispositivos de trabajo y control, al prescribirse un espacio de participación comunitaria -el cual había sido desechado en la normativa

10. Ball sostiene que la característica de publicidad transforma a la inspección y evaluación en un sistema "excesivamente juzgador" (judgemental) (p. 39). 
básica de $1994^{11}$-, en el que se interpela a actores políticos, sociales y educativos locales a asumir parte de esas tareas técnico-administrativas y técnico-pedagógicas ${ }^{12}$ que eran patrimonio exclusivo del aparato burocrático del sistema educativo, representado en este nivel por los consejos escolares y los inspectores distritales. Un órgano colegiado en el espacio municipal (no institucional escolar) encargado de armonizar políticas provinciales y locales, articulando "actividades de educación formal y no formal”, sean éstas elaboradas por la Dirección General o aquellas comunitarias que apruebe. Entre las facultades delegadas, la fundacional será hacerse cargo de "situaciones de emergencia que pudiesen presentarse en el distrito" (Resolución no 6000/03), así como "monitorear", "observar" e "intervenir sobre casos de deserción o no inscripción" (Resolución no 6001/03: Programa Inscripción Total y Control Social del Servicio Educativo).

Se comienza así a concretar un "cambio conceptual en la gestión de los procesos de educación y desarrollo local” (Honorable Legislatura de la Provincia de Buenos Aires, Informe 2004/05: 85). Aunque esta estrategia convocante y descentralizada que se instrumenta desde el área educativa gubernamental no será suficiente, ya que las escuelas públicas por sí solas no lograrán incluir, retener ni contener a parte de esos niños, adolescentes y jóvenes en situación de "riesgo" individual y social ${ }^{13}$. Se convocará también a otros sectores de la comunidad (muchos de ellos con trayectoria previa de autorganización) y otras áreas gubernamentales, traspasando las fronteras de las propias escuelas.

Van emergiendo otras estrategias gubernamentales y no gubernamentales que responderían a una nueva prevención desbordando los límites de las escuelas, a la vez que las cerca también a ellas en un espacio territorial que se separa cada vez más del resto de la comunidad. Dichas estrategias de gobierno se van formalizando en los llamados programas transversales como otra modalidad de esa figura jurídica de los proyectos especiales. Así se instituyen nuevas formas burocráticas creándose, tanto a nivel central como local, consejos o comisiones que se encarguen de la salud, el trabajo, el desarrollo humano y la educación; adquiriendo una nueva significatividad en la vinculación escuela - comunidad - pobreza y abriendo el análisis a las nuevas relaciones que se establecen entre las políticas educativas y las políticas sociales.

II. Véase Giovine (20|0).

12. Terminología utilizada por la legislación para clasificar las tareas del sistema educativo en la Provincia de Buenos Aires desde el siglo XIX.

13. Si bien la matrícula aumentó durante la implementación del nuevo segmento obligatorio, la educación general básica decrece en 1999 y la tasa de repitencia se eleva de un 2,8\% en 1996 al 5 , $1 \%$ en 1999. Mientras que en el nivel medio decrece la matrícula y baja la repitencia (Honorable Legislatura de la Provincia de Buenos Aires, 2000). Asimismo, los jóvenes de 18 a 24 años que no trabajan ni estudian se eleva en 2003 a casi un 20\% a nivel país, el cual es superado por la Provincia de Buenos Aires en 3 puntos. 


\section{Los desplazamientos del asistencialismo escolar hacia la contención educativa}

Antes de analizar uno de los programas transversales -el Plan Más Vida (2002)-, se considera necesario realizar una breve referencia al anterior -el Plan Vida (1994)-, el cual es financiado y administrado por el Ente del gobierno de la Provincia de Buenos Aires, a través del Fondo de Reparación Histórica del Conurbano Bonaerense ${ }^{14}$,creado en 1990. Este Fondo surge de un acuerdo económico entre el gobierno nacional y provincial, constituyéndose durante diez años en el principal ejecutor de programas sociales para "reparar" y "garantizar... derechos humanos básicos" (Ley no 11.247/92). Al mismo tiempo de ser una herramienta política de concentración de poder, construcción de lealtades e identidad política característica del peronismo ${ }^{15}$.

El Plan Vida es la principal estrategia asistencial del gobierno de la Provincia de Buenos Aires para la población materno-infantil (niños de cero a seis años) localizada en barrios con necesidades básicas insatisfechas (NBI) y otras zonas que se consideraban podían albergar madres y nińos con elevados porcentajes de desnutrición y morbimortalidad. La organización se establecía entre un centro a nivel provincial (Ente de Reparación Histórica del Conurbano y Consejo Provincial de la Familia y Desarrollo Humano ${ }^{16}$ ) y los barrios, estando el reparto de alimentos y el seguimiento de las condiciones nutricionales de los beneficiarios a cargo de trabajadoras vecinales voluntarias denominadas "manzaneras" y "comadres"; y siendo sus propios hogares el lugar de distribución. Así se aspiraba a constituir en cada barrio redes solidarias de resolución de problemas sociales.

Pueden señalarse al menos cuatro grandes cuestiones de este plan social. La primera es que esta estrategia de gobernar la pobreza respondía a la lógica asistencialista tradicional ${ }^{17}$, estableciéndose prácticas tutelares y relaciones clientelares con

14. El Conurbano Bonaerense es el cordón que rodea a la ciudad de Buenos Aires y es el área de mayor población de Argentina, representando casi un tercio del total del país. Cabe aclarar que el Plan Vida se aplicó también a otros municipios del resto de la Provincia.

15. Yannuzzi ( 1995) sostiene que el peronismo, a diferencia de los otros partidos políticos, se sustenta en "la subjetividad de un sentimiento de pertenencia... que responde generalmente a la forma en que se produce la construcción imaginaria del peronismo" (p.6l). Y en esta construcción "el principio de lealtad juega, aún incluso a pesar de la crisis de identidad que se introdujo con la implementación de un modelo neoconservador, un papel primordial en el momento de manifestar adhesiones" (p.62). Para observar cómo jugó dicho principio en las relaciones iniciales del sindicalismo docente y el gobierno que facilitaron la sanción de la Ley de Transferencias de los servicios educativos nacionales a las provincias y la Ley Federal de Educación, puede consultarse Giovine (2003).

16. Ley $n^{\circ}$ | I.737/95, modificatoria de la Ley I I.097/9| -Consejo Provincial de la Mujer-.

17. Reparto de alimentos, controles de salud y formación de redes, capacitaciones y proyectos comunitarios. 
el centro de poder político provincial concentrado en el ejecutivo ${ }^{18}$. Prácticas y relaciones que se particularizan e instituyen, tal como sostiene Grassi (2003), a la asistencia social como un recurso de poder discrecional -aún cuando suponga un sentido de justicia social-, personificándose el agente del acto moral de asistencia en la figura del entonces gobernador Eduardo Duhalde y su esposa Hilda González ${ }^{19}$. O en palabras de Bourdieu "dar... termina siendo también una 'manera de poseer'" (en Auyero, 2000: 208), que en este caso genera relaciones de dependencia en un doble movimiento: descendente y horizontal.

La segunda es que produjo una creciente y significativa capacidad organizativa, de liderazgo e intervención de esas mujeres barriales voluntarias en la gestión de conflictos. Esta nueva figura de mediación no estuvo exenta de resistencias y disputas con otros líderes barriales, tales como los punteros políticos y otros representantes de organizaciones de asistencia social laicas o confesionales (Caritas, comedores comunitarios, centros escolares complementarios, de salud, de apoyo escolar, otros planes sociales nacionales, provinciales y municipales, etc.). En esta mediación de distribución de alimentos está implicada una estrategia de gobierno cuyos sentidos oscilan entre la prevención, la intervención moralizante -religiosa o cívica- y la restitución de derechos ciudadanos.

La tercera es que se delimitaba o cercaba un territorio: el barrio con NBI o determinadas manzanas del mismo -Barrio Vida-, convirtiéndolo en un espacio fragmentado de lo social, de lo común. Una micro-comunidad en la cual "se distribuye desigualmente entre sus miembros la carga de la (des)protección” (Dallorso, 2008: 24), apelándose a sus fuerzas autorreguladoras. Territorios que se tornan autorreferenciales y que dificultan los lazos de integración social, ya que se particularizan los problemas, se diversifican las prácticas y no se integran en una res-pública.

La cuarta es que se volvía a apelar a las mujeres ${ }^{20}$ en tanto objetos y sujetos de intervención en políticas materno-educativas; naturalizando la imagen mujer-madre

18. Clientelismo entendido como "el intercambio personalizado de favores, bienes y servicios por apoyo político y votos entre masas y elites" (Auyero, 2000: 181) que en cierta medida resta capacidad para construir "redes horizontales de compromiso cívico" (p. I 82) a las organizaciones de la sociedad civil.

19. Quien presidía el ente que administraba el fondo y -en carácter honorario- el Consejo Provincial de la Familia y Desarrollo Humano. De acuerdo a Chiara, Danani y Filc (2000) la estructura de la Unidad Ejecutora, el Ente de Reparación Histórica del Conurbano Bonaerense -con rango ministerial- mostraba "una debilidad organizacional... [que] parece haber reforzado la centralización de la gestión, llegando incluso a diluir la institucionalidad (en lo que refiere a procedimientos burocráticos, misiones y funciones y mecanismos de control interno) del propio organismo de gestión" (p.237).

20. El ejemplo histórico más paradigmático es la Sociedad de Beneficencia creada en I 823 y que tanta influencia tuvo en la escolarización de las niñas hasta I873. Véase Tenti (1989). La procedencia socioeconómica de las mujeres asistencialistas será una de las principales diferencias entre la Sociedad de Beneficencia y el Plan Vida (damas de caridad y manzaneras, respectivamente). 
y su supuesta capacidad «innata» en la resolución de los problemas considerados domésticos, donde parecieran alojarse las cuestiones de nutrición, organización comunitaria, de salud y desarrollo infantil basada en el "afecto, juego y cuidado" (ejes del Programa de Capacitación Comunitaria en Desarrollo Infantil del Plan Vida en Consejo Provincial de la Familia y Desarrollo Humano, 2000: 188). Hay en este discurso una fuerte interpelación al fortalecimiento moral de un tipo de familia "esencializada" en el rol materno, a veces único referente identitario de menores de familias ya no "nucleares intactas" (pese a que aún permanece en las normas educativas) ${ }^{21}$.

De la conjunción de estos aspectos puede inferirse la interpelación a un nuevo modo de gobernar la pobreza, de participación y representación comunitaria basada en una estrategia de promoción de redes barriales. Se convoca a estas mujeres en tanto buenas vecinas que provienen del mismo lugar al que asisten, a constituirse en líderes comunitarias. Representantes y mediadoras de intereses con capacidad de establecer -en nombre de los asistidos- "acuerdos, ámbitos de discusión y puesta en común" con punteros políticos, funcionarios locales, provinciales y nacionales, profesionales de la salud, miembros de organizaciones sociales, consejeros escolares, inspectores y directores de escuela, entre otros. Representantes políticos, sociales y educativos que son interpelados a participar de un proceso de construcción política "desde una perspectiva descentralizadora" (p. 13) que instituya una nueva "Red Estado - Comunidad" (p. 40).

Es decir que a la vez que promotoras y organizadoras de "prácticas autogestivas y acciones de interrelación barrial", de "agente potencializador en la organización de la comunidad en la que viven" (p. 13), se articulan con y son articuladas por ese centro de poder político que financia y propone una fuerte identificación política con el ejecutivo provincial. Pretensiones de identificación política y de homogeneidad del centro, pero que se irá articulando -a medida que se va diluyendo el Ente de Reparación Histórica del Conurbano- con heterogeneidades locales que se expresan tanto en las características personales de las manzaneras, la composición de los gabinetes sociales ${ }^{22}$ y equipos técnicos - "responsables municipales"- y su vinculación con los niveles nacional, provincial y comunitario; así como aquellas que se relacionan a adscripciones partidarias, objetivos, estrategias e historias particulares que irán definiendo modalidades de "gerenciamiento social" diferentes ${ }^{23}$.

21. Para ampliar la interpelación a la familia en los discursos político-educativos en tanto "agente educador y socializador primario" (artículo 198 de la Constitución Provincial de 1994) o "agente natural y primario" (Artículo $22^{\circ}$ inciso a- de la Ley Provincial de Educación n | I6 | 2/94, véase Giovine y Martignoni (2008).

22. Creación del Gabinete Social Provincial y sus "réplicas a nivel local" (Consejo Provincial de la Familia y Desarrollo Humano, 2000: I0).

23. En el Informe del Plan Vida 1994-1999 se señalan tres tipos, teniendo en cuenta el grado alcanzado en articulación institucional, características del equipo local, participación y concreción 
Prácticas locales que se integran y complementan con las intervenciones estatales, a la vez que incentivan vínculos de solidaridad barrial que refuerzan también estigmatizaciones y vulneración de derechos ciudadanos al trazar esa frontera entre los barrios pobres y no pobres, entre esos sectores de manzanas de mayor riesgo dentro de los pobres.

Una estrategia de gobierno asistencial para pobres cuyos componentes principales persistirán, pese a los re-direccionamientos que tienen lugar luego del Diciembre de 2001. Re-direccionamientos que luchan por imponer otros significantes de promoción social ligados a un enfoque más integral de las políticas y un papel más activo del estado, a la vez que refuerzan el carácter preventivo ligado al mejoramiento de las "condiciones de educabilidad", en tanto "condiciones para el desarrollo integral infantil que aseguren las aptitudes para una mejor inserción en el sistema educativo" (Documento Base del Plan Más Vida, 2002: 16). Es decir, como "el resultado esperado de un proceso de socialización", un atributo del individuo "ampliando ahora su mirada hacia el niño y sus condiciones preexistentes, el niño y la familia, el niño y su bagaje cultural,... recortando sobre la hipótesis del déficit, sus carencias, ahora sociales, culturales, familiares, económicas, lingüísticas, etc.” (Toscano, 2006: 158-159) ${ }^{24}$.

Con la explicitación de este re-direccionamiento se van formalizando vinculaciones entre las políticas sociales y educativas, las cuales se expresan discursivamente en que las primeras también se hagan cargo de cuestiones socioeducativas, tal como las segundas se fueron haciendo cargo de tecnologías de seguridad pública y trabajo social a lo largo del siglo XX. Las pautas de vinculación aparecen explicitadas tanto en los discursos político-educativos como político-sociales. Desde las políticas educativas las condiciones de educabilidad, si bien también se las continúa considerando un atributo individual, se definen como una estrategia de equidad "para hacer posible una participación plena en las tareas de aprendizaje", circunscribiéndoselas a la alimentación, al ingreso y permanencia escolar, al mayor tiempo dentro de las escuelas ${ }^{25}$. Y es en este último donde se explicita más claramente la necesidad de "colocar a este grupo de alumnos dentro de un marco de contenido y resguardo ante las múltiples situaciones de riesgo en que se encuentran inmersos

del objetivo central del Plan: salud. Dichos tipos son: participativo-articulado, de acciones aisladas y centralizado. Véase Consejo Provincial de la Familia y Desarrollo Humano, 2000: I3 | - I 39.

24. Esta postura continúa considerando al aprendizaje como una capacidad natural del individuo, desconociendo su carácter artificial y situacional. Aquí se sostiene que la educabilidad sólo puede ser entendida como "efecto de la interrelación niño-escuela" o, más general, como "la delimitación de las condiciones, alcances y límites que posee potencialmente la acción educativa sobre sujetos particulares en situaciones definidas" (Baquero, 200 I : 7l).

25. Palabras del entonces Director General José O. Bordón (en Honorable Legislatura de la Provincia de Buenos Aires, 200 I ) al presentar el Programa de Comedores Escolares y el Programa Recreativo de Comedores de Verano. 
dado las características de la etapa evolutiva en que se encuentran" (Programa de Jornada Completa en el tercer ciclo de Educación General Básica, 2000).

Un resguardo tutelado que se inscribe en el carácter preventivo de la acción. Esa nueva prevención que asocia a "este grupo de alumnos" -pobres-y a esta "etapa evolutiva"-los adolescentes pobres-; torna confuso diferenciar entre la prevención y la consideración punitiva de dichos sujetos, ya que se parte de la presunción de su potencialidad delictiva (Sozzo, 2005; Dallorso, 2008). Este dispositivo del gobierno de la pobreza se combina con un creciente "sentimiento de inseguridad" de la sociedad argentina que se va instalando en la discusión pública con fuerza de verdad (Kessler, 2009).

Aunque, y tal como se viene afirmando, los programas y proyectos especiales que fueron aumentando significativamente desde el ingreso al siglo XXI y distribuidos selectivamente en las escuelas, ya no alcanzan. Se recurre a políticas sociales que no sólo localizan y fragmentan territorios: el barrio con NBI -el "Barrio Vida" - sectorizado en manzanas a cargo de manzaneras y comadres, en el que habitan y serán merecedores de asistencia sólo aquellos individuos considerados "beneficiarios". En este nuevo plan social se detectan otros significantes que intentan dominar el campo de sentido que porta este discurso de poder: familia - autonomía - comunidad - redes - desarrollo - condiciones de educabilidad - educación popular. Propiciar políticas de estado que favorezcan "el tránsito de la familia-beneficiaria a familia-sujeto protagónico", dotándola de las "estrategias... de resolución de lo alimentario y de las condiciones de desarrollo infantil y familiar". Impartir educación a las familias para que aprendan a operar "con la autonomía necesaria" en un "ámbito comunitario multifamiliar" (Documento Base del Plan Más Vida, 2002: 53 -el resaltado es propio-). Es decir que desde el estado se les dará a esas familias en situación de vulnerabilidad -aún entendida como déficit-, además de alimentos y atención primaria de la salud, educación ya que son también sujetos "de alto riesgo psicosocial" (p. 43), debido a la desprotección producto del fracaso de las políticas económicas de la década de los '90 que precarizaron aún más sus condiciones de vida, expulsándolos del mercado y de su categoría de ciudadanos. Una educación popular concebida como "formación", "al servicio de una transformación social", basada en una "pedagogía de la autonomía” y en el propio "poder de los miembros del grupo-sujeto” (pp. 44-45). Una educación que los libere de la tutela, de la asistencia pública y privada, de ese nomadismo entre las instituciones y organizaciones benefactoras por el que cada vez más crecientemente deambulan los miembros de estas familias pobres ${ }^{26}$.

26. En un estudio realizado en el marco del Proyecto de Asesoramiento en Gestión de Instituciones Educativas (Berg, Duhau y Zubigaray, 2004) se reconstruyó en un barrio con necesidades básicas insatisfechas de una ciudad intermedia de la Provincia el circuito de las madres de un jardín de infantes para la provisión de alimentos, ropa, salud y educación. Véase también Martignoni (2008). 
Por último el significante red, que reiteradamente aparece en estos proyectos y programas especiales, se constituye en una herramienta político-organizativa que diversifica en múltiples agentes -tanto a nivel central como local- la promoción, diseño, implementación y evaluación de políticas. Desde este discurso de poder se pretende crear una "red mixta sociogubernamental" 27 sobre un entramado de redes formales e informales ya preexistentes, con la intención de orientar las relaciones entre el estado y la comunidad a través de "prácticas co-gestivas" y acuerdos entre "actores múltiples"; así como de retornar a esa pretensión de unificación estatal administrando las relaciones sociales entre individuos, grupos e instituciones; fortaleciendo el desarrollo local a la vez que la gobernación de esta porción de la población. Se aglutina en ese espacio cercado del barrio la promoción de acciones, el cuidado, la contención, la prevención y la educación entre aquellos que se constituyen tanto en sujetos como objetos de intervención política.

Otras normas reforzarán estas redes de integración social y educativa apartándose de los confines escolares, sea supliendo, sea superponiendo. Las "madres cuidadoras", los voluntarios de apoyo escolar y las organizaciones que irán siendo reconocidas estatalmente para el cuidado integral de niños ${ }^{28}$-entre otras- van dando lugar a una trama de multi-regulaciones que oscila entre la reparación/restitución de los derechos vulnerados y la no superación de la estigmatización del niño/adolescente/joven pobre - peligroso. Se establecen nuevas alianzas, ya no relativamente estables ni orgánicas tal como las describiera Gramsci, sino más bien particulares en base a representaciones políticas y arreglos institucionales puntuales con otros niveles del estado y sectores de la sociedad civil. Nuevas alianzas que -sustentadas principalmente en la auto-responsabilización- suponen otras juricidades más locales, otras nociones más acotadas de derecho, otras legislaciones que se particularizan o entran en suspenso, cuyo ámbito de aplicación serán los barrios Vida: micro-comunidades en las cuales se recluyen esos individuos y familias que luchan por constituirse en beneficiarios y/o dadores de diferentes planes asistenciales y proyectos especiales, cuyo objetivo estratégico será incluir, retener y contener socio-afectiva y socio-educativamente.

27. "En la red mixta sociogubernamental, los actores provienen del campo de la sociedad civil y del campo estatal... los actores están sometidos a una tensión particular porque tienen que practicar horizontalidad en las relaciones, aunque estén distribuidos en posiciones sociales y gubernamentales jerárquicas y sus relaciones -en varios casos- sean objetivamente verticales" (Programa de Capacitación Estrategia Integral de Cuidado Familiar, Unidad I3: REDES, 2003: 5).

28. Ley $n^{\circ}$ 13574/06, conocida como Ley Segarra. 


\section{Referencias bibliográficas}

AUYERO, J. Cultura política, destitución social y clientelismo político en Buenos Aires. Un estudio etnográfico. In: SVAMPA. Desde abajo. La transformación de las identidades sociales. Buenos Aires: Biblos/Universidad Nacional de General Sarmiento, 2000.

BALL, S. El desempeño, la privatización, los profesionales de la educación y el Estado. Revista Educación y ciudad. Calidad de la educación y políticas públicas, Bogotá: Instituto para la Investigación Educativa y el Desarrollo Pedagógico, n. 14, 2001.

BAQUERO, R. La educabilidad bajo sospecha. Cuadernos de Pedagogía. ano 4, n. 9, 2001. Rosario, Argentina.

BARATTA, A. Política criminal: entre la política de seguridad y la política social. In: CARRANZA (Coord.). Delito y seguridad de los habitantes. México D.F.: Siglo XXI, 1997.

BERG, A.; DUHAU, P. Y.; ZUBIGARAY, P. Informe El vínculo del jardín con la comunidad educativa y demás organizaciones barriales. GIOVINE, R. (Dir.). Proyecto de Asesoramiento Institucional en Gestión Escolar. Facultad de Ciencias Humanas, Universidad Nacional del Centro de la Provincia de Buenos Aires. Buenos Aires: Tandil, 2004.

CASTEL, R. La inseguridad social. ¿Qué es estar protegido? Buenos Aires: Manantial, 2004.

CHIARA, M.; DANANI, C. Y.; FILC, J. Políticas y estilos de gestión de las políticas sociales: el caso del Fondo de Reparación Histórica del Conurbano Bonaerense. In: OSZLAK, O. (Comp.). Estado y Sociedad. Las nuevas reglas del juego. Buenos Aires: Eudeba, 2000. v. 2.

DALLORSO, N. Intervenciones de las trabajadoras vecinales del Plan Más Vida-Comadres en conflictos domésticos y barriales (Gran Buenos, 2005-2007)... Buenos Aires: Instituto de Investigaciones Gino Germani, Facultad de Ciencias Sociales, Universidad de Buenos Aires, 2008. Documentos de Jóvenes Investigadores no 14.

FITOUSSI, J. P.; ROSANVALLON, P. La nueva era de las desigualdades. Buenos Aires: Manantial, 1997.

FOUCAULT, M. La verdad y las formas jurídicas. México: Gedisa, 1983.

GARRETON, M. Política y sociedad entre dos épocas. América Latina en el cambio de siglo. Rosario: Homo Sapiens, 2000.

GARRETON, M. La transformación de la acción colectiva en América Latina. Revista de la CEPAL, n. 76, 2002.

GIOVINE, R. Sindicalismo y gobierno: Proyecto Sindicalismo Docente y Reforma Educativa en América Latina. Buenos Aires: PREAL/FLACSO, 2003.

GIOVINE, R. Cultura politica, ciudadanía y gobierno escolar. Tensiones en torno a su definición: la provincia de Buenos Aires (1850-1905). Buenos Aires: Editorial Stella. La Crujía, 2008. Colección Itinerarios. 
GIOVINE, R.; MARTIGNONI, L. Nuevas y viejas interpelaciones a la familia en el discurso escolar. Revista Propuesta Educativa, n. 30. FLACSO, 2008.

GRASSI, E. Politicas y problemas sociales en la sociedad neoliberal. La otra década infame (I). Buenos Aires: Espacio Editorial, 2003.

HALPERIN DONGHI, T. Proyecto y construcción de una nación (Argentina 1846-1880). Caracas: Biblioteca Ayacucho, 1980.

KESSLER, G. El sentimiento de inseguridad. Buenos Aires: Siglo XXI, 2009.

LANZARO, J. (Ed.). Tipos de presidencialismo y coaliciones políticas en América Latina. Buenos Aires: CLACSO, 2001.

MARTIGNONI, L. Escuelas y experiencias adolescentes en el gobierno de la pobreza. 2008. Tese. (Doutorado em Ciências Sociais)- FLACSO, Buenos Aires, Argentina, 2008.

NOVARO, M. Presidentes, equilibrios institucionales y coaliciones de gobierno en Argentina (1989-2000). In: LANZARO (Ed.). Tipos de presidencialismo y coaliciones políticas en América Latina. Buenos Aires: CLACSO, 2001.

OSBORNE, D.; GAEBLER, T. La reinvención del gobierno. La influencia del espiritu empresarial en el sector público. Barcelona: Paidós, 1994.

PINEAU, P. La escolarización de la Provincia de Buenos Aires (1875-1930). Una versión posible. Buenos Aires: Oficina de Publicaciones del CBC/UBA-FLACSO, 1997.

SOZZO, M. (Dir.). Policía, violencia, democracia. Ensayos sociológicos. Santa Fe: Ediciones UNL, 2005.

SVAMPA, M. Desde Abajo. La transformación de las identidades sociales. Buenos Aires: Biblos/Universidad Nacional de General Sarmiento, 2000.

SVAMPA, M. Los que ganaron. La vida en los countries y barrios privados. Buenos Aires: Biblos/Universidad Nacional de General Sarmiento, 2002.

TENTI FANFANI, E. Estado y pobreza: estrategias típicas de intervención. Buenos Aires: Centro Editor de América Latina, 1989. Tomos 1 e 2.

TOSCANO A. G. La educabilidad y la definición del destino escolar de los niños. Los legajos escolares como superficie de emergencia. Revista Espacios en Blanco. Buenos Aires, n. 16, 2006.

YANNUZZI, M. A. La modernización conservadora. El Peronismo de los 90. Buenos Aires: Editorial Fundación Ross, 1995.

Documentos citados

BUENOS AIRES (Província). Consejo provincial de la familia y desarrollo humano. Informe de Evaluación del Plan Vida: 1994-1999, 2000. Plan Vida, 2000.

BUENOS AIRES (Província). Dirección general de cultura y educación de la Provincia de Buenos Aires: Selección de proyectos y programas 1999-2006. Selección de resoluciones 1999-2006. 
BUENOS AIRES (Província). Honorable legislatura de la Provincia de Buenos Aires. Recopilación de legislación educativa 1990-2006. Informes de la Dirección General de Cultura y Educación 2001-2006.

BUENOS AIRES (Província). Ministerio de Desarrollo Humano y Trabajo de la Provincia de Buenos Aires. Documento Base del Plan Más Vida, 2002, 2008.

Programa de Capacitación Estrategia Integral de Cuidado Familiar. REDES, 2003.

Recebido em 15 de julho de 2011 e aprovado em 23 de setembro de 2011. 